Опыт применения селективного ингибитора фосфодиэстеразы-4 рофлумиласта (Даксас) у пациентов с хронической обструктивной болезнью легких и метаболическим синдромом

\author{
Г.Л.Иенатова, Е.В.Блинова, М.С.Бельснер, И.В.Греонева
}

ГБОУ ВПО «Южно-Уральский государственный медицинский университет» Минздрава России: 454096, Челябинск, ул. Воровского, 64

\title{
Резюме
}

Цель. Изучение эффективности и безопасности применения препарата рофлумиласт (Даксас) в дозе 500 мг в сутки у больных хронической обструктивной болезнью легких (ХОБЛ) и метаболическим синдромом (МС) в дополнение к базисной терапии. Материалы и методы. В Городском консультативно-диагностическом центре для больных пульмонологического профиля при ГБУЗ «Областная клиническая больница № 4» (Челябинск) проведено комплексное клинико-функциональное исследование среди пациентов мужского пола $(n=42)$ с ХОБЛ III-IV степени в сочетании с МС и частыми обострениями ХОБЛ ( $\geq 2$ раз в год). Результаты. Применение рофлумиласта у пациентов с ХОБЛ и МС сопровождается улучшением клинических, лабораторных и функциональных показателей и снижением частоты обострений ХОБЛ.

Ключевые слова: хроническая обструктивная болезнь легких, метаболический синдром, обострения, рофлумиласт.

DOI: 10.18093/0869-0189-2016-26-3-323-327

\section{An experience of therapy of patients with chronic obstructive pulmonary disease and metabolic syndrome with selective phosphodiesterase-4 inhibitor roflumilast}

\author{
G.L.Ignatova, E.V.Blinova, M.S.Bel'sner, I.V.Grebneva \\ South Ural State Medical University, Healthcare Ministry of Russia: 64, Vorovskogo str., Chelyabinsk, 454092, Russia
}

\section{Summary}

The aim of this study was to evaluate clinical efficacy and safety of selective phosphodiesterase- 4 inhibitor roflumilast in patients with COPD and metabolic syndrome. Methods. In this prospective study, patients with stage III - IV COPD, frequent exacerbation phenotype ( $\geq 2$ per a year) and metabolic syndrome ( $n=42)$ were treated with roflumilast (Daxas) $500 \mathrm{mg}$ q.d. additionally to the basic therapy for 12 months. Clinical investigation, mMRC scale and CAT questionnaire, pulse oxymetry, spirometry, 6-min walking test, measurement of glucose, lipids and C-reactive protein in blood were used in all patients. Results. Exacerbation rate decreased in patients with COPD treated with roflumilast. FEV $\mathrm{F}_{1}$ and quality of life improved in patients treated with roflumilast. Therapy with roflumilast was associated with statistically significant reduction in the waist circumference without significant change in the body weight, waist-to-hip ratio or body mass index. Conclusion. Therapy with roflumilast was associated with improvement in clinical, laboratory and functional parameters and reduction in exacerbation rate in patients with COPD and metabolic syndrome. Key words: chronic obstructive pulmonary disease, metabolic syndrome, exacerbation, roflumilast.

Хроническая обструктивная болезнь легких (ХОБЛ) хроническое воспалительное заболевание дыхательных путей, паренхимы легких и легочных кровеносных сосудов, возникающее в результате воздействия поступающих с воздухом раздражителей, таких как табачный дым и другие загрязняющие факторы внешней среды. Для ХОБЛ характерно неуклонно прогрессирующее снижение функции внешнего дыхания (ФВД) - это специфичный функциональный и прогностический признак заболевания. Изменения ФВД и частота обострений легли в основу общепринятой классификации ХОБЛ (2011) и стали главной терапевтической «мишенью» в крупных клинических исследованиях.

В современном определении ХОБЛ особо выделено, что у ряда пациентов обострения и сопутствующие заболевания могут влиять на общую тяжесть ХОБЛ [1]. В некоторых случаях сопутствующие заболевания у этой категории больных рассматрива- ются как результат системного воспаления [2, 3]. Среди многочисленных сопутствующих заболеваний наибольшее влияние на тяжесть ХОБЛ оказывают сердечно-сосудистые заболевания (СС3), метаболический синдром (МС) и сахарный диабет (СД). Ведущая причина гибели больных ХОБЛ II и III степени - не хроническая дыхательная недостаточность, как традиционно принято считать, а СС3, являющиеся компонентами МС - ишемическая болезнь сердца (ИБС), артериальная гипертензия [4].

Экспертами Всемирной организации здравоохранения (BO3) MC характеризуется как пандемия XXI века [5]. Распространенность МС составляет 20-40\% и чаще встречается у лиц среднего и старшего возраста [6]. По данным ВО3 (2010) в Российской Федерации избыточная масса тела либо ожирение отмечаются у 46,5\% мужчин и 51,7\% женщин [5]. Уровень заболеваемости СС3 и смертности у пациентов с МС существенно выше по сравнению с лица- 
ми без такового [6]. Совокупность этих социально значимых заболеваний отражает этап новых болезней наступившего века. Компоненты МС, с одной стороны, а также нарушение бронхиальной проходимости и снижение легочной функции - с другой, могут взаимно потенцировать друг друга [7].

\section{Воспаление дыхательных путей при ХОБЛ}

\section{Маркеры системного воспаления}

Хроническое воспаление играет ключевую роль в патогенезе ХОБЛ, его механизмы достаточно сложны, однако важно выделить его принципиальные особенности. Воспаление носит системный характер, приводя к морфологическим изменениям в легких бронхоконстрикции, отеку слизистой оболочки бронхов, гиперсекреции слизи, эмфиземе, что в совокупности ограничивает проходимость дыхательных путей [3]. Под влиянием провоспалительных цитокинов возникают поражения сердечно-сосудистой системы, скелетной мускулатуры (апоптоз миоцитов), анемический синдром, остеопения, депрессивные состояния, метаболические нарушения. В случае прогрессирования болезни нарастает главный признак заболевания - хроническая дыхательная недостаточность.

Основными клетками, принимающими участие в воспалительном процессе, являются нейтрофилы, Т-лимфоциты $\left(\mathrm{CD}^{+}\right)$и макрофаги [2, 3]. Нейтрофилы играют важнейшую роль в развитии ХОБЛ. Наряду с выделением ряда провоспалительных медиаторов, обладающих хемотаксическим действием для других нейтрофилов - вазоактивных простагландинов, эти клетки выделяют ряд ферментов, в первую очередь - нейтральные протеазы (эластин), а также кислородные радикалы. В норме этот комплекс компонентов направлен на разрушение чужеродных субстанций, попавших во внутреннюю среду. Наряду с нейтрофилами в формирование воспаления вносят свой вклад макрофаги, Т-лимфоциты, эозинофилы и эпителиальные клетки. Макрофаги скапливаются в местах повреждения межальвеолярных перегородок, участвуют в регуляции воспаления путем секреции медиаторов (фактор некроза опухоли (TNF- $\alpha$ ), интерлейкин (IL)-8, лейкотриен B4), усиливающих нейтрофильное воспаление. В периферической крови, мокроте и конденсате выдыхаемого воздуха у пациентов с ХОБЛ наблюдается повышение маркеров воспаления - С-реактивного белка (СРБ), фибриногена, IL-6, IL-8, TNF- $\alpha$, лейкотриена B4 [8, 9]. Уровни данных биомаркеров, определяемых в периферической крови или в конденсате выдыхаемого воздуха, ассоциированы с показателями, отражающими тяжесть заболевания.

Наличие системного воспаления у больных ХОБЛ стабильного течения показано в метаанализе W.Q.Gan et al., в который были включены 14 исследований, посвященных изучению маркеров системного воспаления при ХОБЛ [10]: уровень провоспалительных цитокинов и других медиаторов у больных ХОБЛ значительно превышал показатели в группах сравнения: СРБ - на 1,86 мг / л (95\%-ный доверительный интервал (ДИ) - 0,75-2,97); фибриноген - на 0,37 г / л (95\%-ный ДИ - 0,18-0,56); TNF- $\alpha$ - на 2,64 пг / мл (95\%-ный ДИ - 0,44-5,72); лейкоциты крови - на 0,88 × $10^{9}$ клеток / л $(95 \%$-ный ДИ - 0,36-1,40). Показано, что выраженность воспалительного ответа у пациентов с ХОБЛ прогрессивно повышалась по мере прогрессирования заболевания, т. е. снижения показателя объема форсированного выдоха за 1-ю секунду $\left(\mathrm{OФB}_{1}\right)$ [10].

\section{Сердечно-сосудистые эффекты}

По результатам крупных эпидемиологических исследований продемонстрировано, что ведущей причиной смерти больных ХОБЛ легкого и среднетяжелого течения являются сердечно-сосудистые события [11, 12]. Данная патология обнаруживается не менее чем у $50 \%$ больных ХОБЛ [13]. Причиной частой ассоциации ХОБЛ и СС3 может быть общий фактор риска - курение [14], а также прием некоторых лекарственных средств, повышающих симпатическую активность нервной системы $\left(\beta_{2}\right.$-агонисты и т. п.) [15]. В настоящее время накапливается все больше данных о том, что персистирующее системное воспаление при ХОБЛ вносит свой вклад в патогенез атеросклероза и развитие кардиологической патологии у пациентов с обструктивной болезнью [14, 15]. В исследовании NHNES III показано, что у лиц с тяжелой бронхиальной обструкцией $\left(\mathrm{OФB}_{1}<50 \%\right)$ в 2,18 раза чаще отмечались повышенные ( $\geq 2,2$ мг / л) и в 2,74 раза - высокие (> 10 мг / л) уровни СРБ по сравнению с лицами без бронхиальной обструкции (с поправкой на возраст, пол, курение, индекс массы тела (ИМТ), сопутствующие заболевания). СРБ белок активной фазы, повышенный при воспалительных процессах (в т. ч. при СД, ожирении), при его помощи могут усиливаться продукция других цитокинов и адгезия лейкоцитов сосудистым эндотелием (увеличение воспалительного каскада), активируется система комплемента, стимулируется захват липопротеинов низкой плотности макрофагами [16]. Согласно недавно полученным данным, наличие хронического системного воспаления и связанные с ним повышенные уровни TNF- $\alpha$, IL-6 и СРБ являются причиной развития инсулинорезистентности и СД [17].

\section{Роль фосфодиэстеразы 4-го типа (ФДЭ-4) в воспалении при ХОБЛ}

Несмотря на сложность и многогранность воспаления при ХОБЛ, в нем присутствуют ключевые звенья, одним из которых является ФДЭ-4 - энзим, регулирующий метаболизм циклического аденозинмонофосфата (цАМФ) в провоспалительных и иммунных клетках, а также катализирующий переход цАМФ в его неактивную форму - АМФ. Ингибиторы ФДЭ-4 тормозят разрушение цАМФ и способствуют поддержанию высоких внутриклеточных уровней цАМФ, что снижает активность провоспалительных функций клеток. Наряду с подавлением всех фаз воспаления (синтез и продукция провоспа- 
лительных цитокинов, выделение свободных радикалов, пролиферация фибробластов, выделение протеолитических ферментов) при ингибировании ФДЭ-4 наблюдается нарастание глюкозозависимой секреции инсулина и усиление липолиза.

Способность ингибировать ФДЭ обнаружена в свое время у применяемого с 1930-х гг. теофиллина, однако его применение было ограничено большим числом лекарственных взаимодействий и узким диапазоном терапевтических доз, что обусловило частые нежелательные явления со стороны сердечно-сосудистой системы и желудочно-кишечного тракта [18]. Поиск новых молекул привел к созданию селективных ингибиторов ФДЭ-4 II поколения, таких как циломиласт и рофлумиласт. В настоящее время для широкого клинического применения доступен ингибитор ФДЭ-4 рофлумиласт, зарегистрированный под торговым названием Даксас (таблетки по 500 мг для приема 1 раз в сутки).

Целью исследования явилась оценка эффективности и безопасности применения селективного ингибитора ФДЭ-4 в комплексной терапии пациентов с ХОБЛ и МС.

\section{Материалы и методы}

На базе Городского консультативно-диагностического центра для больных пульмонологического профиля при ГБУЗ «Областная клиническая больница № 4» (Челябинск) у пациентов с ХОБЛ и МС проведено проспективное комплексное клинико-функциональное исследование по изучению эффективности и безопасности применении препарата рофлумиласт (Даксас) в дозе 500 мг в сутки. Все пациенты в течение 12 мес. в дополнение к базисной терапии ХОБЛ получали рофлумиласт (Даксас) 500 мг в сутки.

Критерии включения в исследование: мужчины старше 50 лет с ХОБЛ III-IV степени (GOLD, 2011) в сочетании с МC (артериальная гипертензия, ожирение, СД или нарушенная толерантность к глюкозе), длительность заболевания $\geq 2$ лет, наличие в анамнезе $\geq 2$ обострений ХОБЛ за 1 год. Диагноз ХОБЛ выставлялся на основании критериев постановки диагноза GOLD (2011), а MC - согласно классификации ВНОК (2010). Исследование проводилось вне фазы обострения ХОБЛ.

В исследование включены пациенты мужского пола ( $n=42$; средний возраст $-65,5 \pm 6,23$ года). Всем больным проведены клинические и инструментальные исследования: пульсоксиметрия, спирография с помощью аппарата Microlab (MicroMedical Ltd., Великобритания). Для определения уровня физической активности использовался 6-минутный шаговый тест. Степень одышки оценивалась по шкале mMRC от 0 до 4 баллов. Оценивалась частота обострений ХОБЛ, в т. ч. в случаях, когда требовалась госпитализация. При помощи COPD Assessment Test (CAT) проводился клинический анализ влияния ХОБЛ на самочувствие пациента и его повседневную жизнь. У всех наблюдаемых пациентов проводилось исследование углеводного профиля (гликированный гемоглобин, глюкоза крови натощак), липидный профиль (содержание общего холестерина (OXC), липопротеинов низкой ЛПНП) и высокой (ЛПВП) плотности, триглицеридов (ТГ)), оценивался уровень СРБ. Анализ данных показателей проводился исходно (до начала терапии рофлумиластом) и через 12 мес.

Все пациенты в течение 12 мес. получали ингибитор ФДЭ-4 рофлумиласт в дозе 500 мг в сутки в дополнение к базисной терапии ХОБЛ. Терапия, в т. ч. базисная, не менялась в течение всего периода исследования и включала длительно действующие $\beta_{2}$-агонисты, длительно действующие антихолинергические препараты и ингаляционные глюкокортикостероиды.

У вошедших в исследование больных ХОБЛ отмечалось тяжелое и крайне тяжелое (в 26,2 \% случаев - III степени, в 73,8 \% - IV степени) течение заболевания, длительность которого составила $8,8 \pm$ 3,96 года. В период проведения исследования 45,2 \% участников являлись активными курильщиками, 54,8 \% - экс-курильщиками; у всех участников установлен достаточно высокий индекс курения - 39,9 \pm 12,9 пачко-лет, а также выявлены тяжелые обструктивные изменения (средний показатель ОФВ 1 до начала терапии составил 39,56 $\pm 1,57 \%)$.

Из сопутствующих заболеваний у 88,1 \% выявлена гипертоническая болезнь, проявления ИБС наблюдались у 78,6 \%, СД 2-го типа - у 35,7 \% пациентов. Сопутствующая лекарственная терапия была сопоставима в обеих группах.

\section{Результаты и обсуждение}

Основным критерием МС является абдоминальное ожирение, для оценки которого определяется окружность талии (ОТ). У всех включенных в исследование пациентов отмечено центральное (абдоминальное) ожирение, ОТ до лечения составила 108,4 \pm 11,5 см. Исходный ИМТ составил 28,39 $\pm 3,1$ кг / м², у $57,1 \%-<30$ кг / м², что соответствует избыточной массе тела, ожирение I степени диагностировано у 42,9 \% пациентов (табл. 1).

На фоне терапии рофлумиластом выявлено статистически значимое уменьшение окружности талии, при этом существенной динамики массы тела, ОТ / ОБ и ИМТ не получено (см. табл. 1).

\section{Таблица 1 \\ Динамика основных антропометрических параметров на фоне терапии рофлумиластом}

Table 1

Change in basic anthropometric parameters in patients treated with roflumilast

\begin{tabular}{l|c|c|c}
\multicolumn{1}{c|}{ Показатель } & До лечения & После лечения & p \\
ОТ, см & $108,4 \pm 11,5$ & $106,07 \pm 11,00^{*}$ & $<0,05$ \\
ОТ / ОБ, см & $0,98 \pm 0,04$ & $0,96 \pm 0,03$ & $>0,05$ \\
Масса тела, кг & $85,4 \pm 0,4$ & $83,97 \pm 8,90$ & \\
ИМТ, кг / м² & $28,39 \pm 3,10$ & $27,04 \pm 2,78$ & \\
Примечание: * $-p<0,05$. & & \\
Note. ${ }^{*}, p<0.05$.
\end{tabular}


Отмечено достоверное снижение числа обострений: до начала терапии рофлумиластом среднее число обострений составило $2,58 \pm 0,58$ в год, а через 12 мес. - до $0,95 \pm 0,57(p<0,005)$

Также отмечено статистически достоверное улучшение самочувствия по САТ: до лечения суммарный балл составлял $29,00 \pm 3,51$, а через 12 мес. $-24,78 \pm$ $3,17$ ( $p<0,005)$, что свидетельствует о высокой терапевтической эффективности данного препарата.

На фоне приема препарата, не являющегося бронхолитическим, отмечено увеличение ОФВ 1 , что можно объяснить корреляцией степени бронхиальной обструкции с выраженностью воспаления в дыхательных путях при ХОБЛ. Показано, что при использовании рофлумиласта снижается активность воспаления и таким образом улучшается состояние бронхиальной проходимости (табл. 2).

При анализе изменений лабораторных параметров исходно и через 12 мес. терапии рофлумиластом выявлено достоверное уменьшение выраженности воспаления, а именно - уровня СРБ (табл. 3), что клинически проявилось снижением числа обострений ХОБЛ и улучшением вентиляционных показателей $\left(O \Phi B_{1}\right)$. На фоне лечения рофлумиластом отмечено улучшение показателей липидного спектра (ОХС и ЛПВП), при этом изменений уровня ТГ и ЛПНП не получено, что свидетельствует о высоком риске сердечно-сосудистых осложнений у пациентов с ХОБЛ и МС.

Таблица 2 Динамика клинико-функциональных показателей на фоне терапии рофлумиластом Table 2

Change in clinical and functional parameters in patients treated with roflumilast

\begin{tabular}{|c|c|c|c|}
\hline Показатель & До лечения & После лечения & $p$ \\
\hline САТ, баллы & $29,00 \pm 3,51$ & $24,78 \pm 3,17^{\star *}$ & $<0,005$ \\
\hline Число обострений & $2,58 \pm 0,58$ & $0,95 \pm 0,57^{* *}$ & \\
\hline $0 \Phi B_{1}, \%$ & $39,56 \pm 1,57$ & $45,01 \pm 0,57^{*}$ & $<0,05$ \\
\hline
\end{tabular}

Примечание: * $-p<0,05 ;{ }^{* *}-p<0,005$

Note. ${ }^{*}, p<0.05 ;{ }^{* *}, p<0.005$

Таблица 3

Динамика лабораторных показателей на фоне терапии рофлумиластом

Table 3

Change in laboratory parameters in patients treated with roflumilast

\begin{tabular}{l|r|r|c}
\multicolumn{1}{c|}{ Показатель } & До лечения & После лечения & \multicolumn{1}{c}{$p$} \\
\hline САТ, баллы & $29,00 \pm 3,51$ & $24,78 \pm 3,17^{* *}$ & $<0,005$ \\
СРБ, мг & $6,63 \pm 0,76$ & $4,56 \pm 1,86^{* *}$ & $<0,005$ \\
ОХС, ммоль / л & $5,35 \pm 0,24$ & $4,39 \pm 0,92^{*}$ & $<0,05$ \\
ЛПВП, ммоль / л & $1,50 \pm 0,32$ & $1,69 \pm 1,06^{*}$ & \\
ЛПНП, ммоль / л & $3,46 \pm 1,03$ & $3,22 \pm 0,97$ & $>0,05$ \\
ТГ, ммоль / л & $1,67 \pm 0,41$ & $1,50 \pm 0,33$ & \\
$\begin{array}{l}\text { Уровень глюкозы } \\
\text { натощак, ммоль / л }\end{array}$ & $5,58 \pm 1,09$ & $5,09 \pm 0,50^{*}$ & $<0,05$
\end{tabular}

Примечание: * $-p<0,05 ;{ }^{* *}-p<0,005$.

Note. ${ }^{*}, p<0.05 ;{ }^{* *}, p<0.005$.
В течение 12-месячного наблюдения случаев изменений уровня гликемии в сторону его патологического увеличения не выявлено. У пациентов с исходным уровнем глюкозы натощак $>$ 5,5 ммоль / л к концу исследования отмечено статистически значимое снижение данного показателя на 16,4 \% (в среднем с 6,70 \pm 0,18 до 5,60 \pm 0,17 ммоль / л), что отражает благоприятное влияние рофлумиласта на гликемический профиль у больных ХОБЛ с сопутствующим СД (см. табл. 3).

Наиболее частыми побочными эффектами терапии рофлумиластом в данном исследовании явились снижение аппетита $(11,9 \%)$, диарея $(9,5 \%)$, тошнота $(7,1 \%)$ и бессонница $(4,8 \%)$. Все нежелательные явления были легкими и умеренно выраженными, возникали в первые 2 нед. терапии, в дальнейшем разрешались и в большинстве случаев не потребовали отмены препарата и прекращения участия в исследовании. От дальнейшего приема препарата в связи с выраженным нарушением сна отказался только 1 пациент.

\section{Заключение}

На основании изложенного сделаны следующие выводы:

- у лиц с частыми обострениями в анамнезе при применении рофлумиласта (Даксас ${ }^{\circledR}$ ) снижается их частота, что является одной из основных целей лечения пациентов с ХОБЛ;

- применение рофлумиласта у пациентов с ХОБЛ в сочетании с МС в дополнение к базисной терапии сопровождалось достоверным увеличением $\mathrm{OФB}_{1}$ и улучшением показателей качества жизни по шкале САT;

- на фоне терапии рофлумиластом выявлено статистически значимое уменьшение ОТ, при этом существенной динамики массы тела, ОТ / ОБ и ИМТ не получено.

\section{Литература}

1. Федеральные клинические рекомендации по диагностике и лечению хронической обструктивной болезни легких. М.: РРО; 2013.

2. Fabbri L.M., Luppi F., Beghe B., Rabe K.F. Complex chronic comorbidities of COPD. Eur. Respir. J. 2008; 31: 2014-2012.

3. Loscalzo J. System's biology and personalized medicine: a network approach to human disease. Proc. Am. Thorac. Soc. 2011; 8: 196-198.

4. Thomsen M., Dahl M., Lange P. et al. Inflammatory biomarkers and comorbidities in chronic obstructive pulmonary disease. Am. J. Respir. Crit. Care Med. 2012; 186: 982-988.

5. http://www.who.int/respiratory/copd/burden/en/index.html

6. Sin D.D., Man S.F. Why are patients with COPD at increased risk of cardiovascular diseases? Circulation. 2003; 107 (11): 1514-1519.

7. Чучалин А.Г. Хроническая обструктивная болезнь легких и сопутствующие заболевания. Русский медицинский журнал. 2008; 2: 58-64. 
8. Chung K.F. Inflammatory mediators in chronic obstructive pulmonary disease. Curr. Drug Targets Inflamm. Allergy. 2005; 4 (6): 619-625.

9. Pinto-Plata V.M., Mullerova H., Toso J.F. et al. C-reactive protein in patients with COPD, control smokers and nonsmokers. Thorax. 2006; 61: 23-28.

10. Gan W.Q., Man S.F., Senthilselvan A., Sin D.D. The association between chronic obstructive pulmonary disease and systemic inflammation: a systematic review and a metaanalysis. Thorax. 2004; 59: 574-580.

11. Hole D.J., Watt G.C., Davey-Smith G. et al. Impaired lung function and mortality risk in men and women: findings from Renfrew and Paisley prospective population study. Br. Med. J. 1996; 313: 711-775.

12. Anthonisen N.R., Connett J.E., Enright P.L., Manfreda J. Lung Health Study Research Group. Hospitalizations and mortality in the Lung Health Study. Am. J. Crit. Care Med. 2002; 166: 333-339.

13. Sin D.D., Wu. L., Man S.F. The relationship between reduced lung function and cardiovascular mortality: a population-based study and a systematic review of the literature. Chest. 2005; 127: 1952-1959.

14. Anthonisen N.R., Connett J.E., Kiley J.P. et al. Effects of smoking intervention and the use of an inhaled anticholinergic bronchodilatator on the rate of decline of $\mathrm{FEV}_{1}$ : the Lung Health Study. JAMA. 1994; 272: 1497-1505.

15. Heindl S., Lehnert M., Criee C.P. et al. Marked sympathetic activation in patients with chronic respiratory failure. Am. J. Respir. Crit. Care Med. 2001; 164: 597-601.

16. Verma S., Li S.H., Badiwala M.V. et al. Endothelin antagonism and interleukin-6 inhibition attenuate the proatherogenoc effects of C-reactive protein. Circulation. 2002; 105: 1890-1896.

17. Wellen K.E., Hotamisligil G.S. Inflamation, stress and diabetes. J. Clin. Invest. 2005; 115: 1111-1119.

18. Boswell-Smith V., Spina D. PDE4 inhibitors as potential therapeutic agents in the treatment of COPD-focus on roflumilast. Int. J. Chron. Obstruct. Pulm. Dis. 2007; 2 (2): 121-129.

удк [616.24-036 12-06:616-008. Поступила 13.04.16

\section{References}

1. Federal Clinical Guidelines on Diagnosis and Management of Chronic Obstructive Pulmonary Disease. Moscow: RRO, 2013 (in Russian).

2. Fabbri L.M., Luppi F., Beghe B., Rabe K.F. Complex chronic comorbidities of COPD. Eur. Respir. J. 2008; 31: 2014-2012.

3. Loscalzo J. System's biology and personalized medicine: a network approach to human disease. Proc. Am. Thorac. Soc. 2011; 8: 196-198.

4. Thomsen M., Dahl M., Lange P. et al. Inflammatory biomarkers and comorbidities in chronic obstructive pulmonary disease. Am. J. Respir. Crit. Care Med. 2012; 186: 982-988.

5. http://www.who.int/respiratory/copd/burden/en/index.html

6. Sin D.D., Man S.F. Why are patients with COPD at increased risk of cardiovascular diseases? Circulation. 2003; 107 (11): 1514-1519.

7. Chuchalin A.G. Chronic obstructive pulmonary disease and comorbidity. Russkiy meditsinskiy zhurnal. 2008; 2: 58-64 (in Russian).

8. Chung K.F. Inflammatory mediators in chronic obstructive pulmonary disease. Curr. Drug Targets Inflamm. Allergy. 2005; 4 (6): 619-625.
9. Pinto-Plata V.M., Mullerova H., Toso J.F. et al. C-reactive protein in patients with COPD, control smokers and nonsmokers. Thorax. 2006; 61: 23-28.

10. Gan W.Q., Man S.F., Senthilselvan A., Sin D.D. The association between chronic obstructive pulmonary disease and systemic inflammation: a systematic review and a metaanalysis. Thorax. 2004; 59: 574-580.

11. Hole D.J., Watt G.C., Davey-Smith G. et al. Impaired lung function and mortality risk in men and women: findings from Renfrew and Paisley prospective population study. Br. Med. J. 1996; 313: 711-775.

12. Anthonisen N.R., Connett J.E., Enright P.L., Manfreda J. Lung Health Study Research Group. Hospitalizations and mortality in the Lung Health Study. Am. J. Crit. Care Med. 2002; 166: 333-339.

13. Sin D.D., Wu. L., Man S.F. The relationship between reduced lung function and cardiovascular mortality: a population-based study and a systematic review of the literature. Chest. 2005; 127: 1952-1959.

14. Anthonisen N.R., Connett J.E., Kiley J.P. et al. Effects of smoking intervention and the use of an inhaled anticholinergic bronchodilatator on the rate of decline of $\mathrm{FEV}_{1}$ : the Lung Health Study. JAMA. 1994; 272: 1497-1505.

15. Heindl S., Lehnert M., Criee C.P. et al. Marked sympathetic activation in patients with chronic respiratory failure. Am. J. Respir. Crit. Care Med. 2001; 164: 597-601.

16. Verma S., Li S.H., Badiwala M.V. et al. Endothelin antagonism and interleukin-6 inhibition attenuate the proatherogenoc effects of C-reactive protein. Circulation. 2002; 105: 1890-1896.

17. Wellen K.E., Hotamisligil G.S. Inflamation, stress and diabetes. J. Clin. Invest. 2005; 115: 1111-1119.

18. Boswell-Smith V., Spina D. PDE4 inhibitors as potential therapeutic agents in the treatment of COPD-focus on roflumilast. Int. J. Chron. Obstruct. Pulm. Dis. 2007; 2 (2): 121-129.

Received April 13, 2016 UDC [616.24-036.12-06:616-008.9]-085.355.015.23

\section{Информация об авторах}

Игнатова Галина Львовна - Д. М. н., профессор, заведующая кафедрой терапии ФДПО ГБОУ ВПО «Южно-Уральский государственный медицинский университет» Минздрава России; тел.: (351) 742-66-40; e-mail: iglign@mail.ru

Блинова Елена Владимировна - к. м. н., ассистент кафедры терапии ФДПО ГБОУ ВПО «Южно-Уральский государственный медицинский университет» Минздрава России; тел.: (351) 742-82-57; e-mail: blinel @mail.ru

Бельснер Мария Сергеевна - аспирант кафедры терапии ФДПО ГБОУ ВПО «Южно-Уральский государственный медицинский университет» Минздрава России; тел.: (351) 742-82-57; e-mail: mariika 04@mail.ru Гребнева Ирина Викторовна - к. М. Н., доцент кафедры терапии ФДПО ГБОУ ВПО «Южно-Уральский государственный медицинский университет» Минздрава России; тел.: (351) 742-82-57; e-mail: grebneviv @mail.ru

\section{Author information}

Ignatova Galina L'vovna, MD, Professor, Head of Department of Therapy, Faculty of Postgraduate Physician Training, South Ural State Medical University, Healthcare Ministry of Russia; tel.: (351) 742-66-40; e-mail: iglign@mail.ru

Blinova Elena Vladimirovna, PhD, Assistant Lecturer at Department of Therapy, Faculty of Postgraduate Physician Training, South Ural State Medical University, Healthcare Ministry of Russia; tel.: (351) 742-82-57; e-mail: blinel@mail.ru

Bel'sner Mariya Sergeevna, PhD student at Department of Therapy, Faculty of Postgraduate Physician Training, South Ural State Medical University, Healthcare Ministry of Russia; tel.: (351) 742-82-57; e-mail: mariika_04 @mail.ru

Grebneva Irina Viktorovna, $\mathrm{PhD}$, Associate Professor at Department of Therapy, Faculty of Postgraduate Physician Training, South Ural State Medical University, Healthcare Ministry of Russia; tel.: (351) 742-82-57; e-mail: grebneviv@mail.ru 